\title{
The Effect of Cutting Parameters on Tool Vibration During Magnetorheological Fluid Controlled Turning Bar
}

\author{
P. Sam Paul \\ Department of Mechanical Engineering, Karunya University, Coimbatore, 641114, Tamilnadu, India
}

\author{
Kolhar Sudeep Sunil \\ Marini India-Fayat Group, Gujarat 382110, India
}

\author{
A. S. Varadarajan \\ Nehru College of Engineering and Research Centre, Sampaul Thrissur, 678506, Kerala, India
}

(Received 27 August 2014; accepted 6 October 2014)

\begin{abstract}
Tool vibration is a dynamic instability of the cutting process, which is a result of the interaction between the metal cutting process and the dynamics of a machine tool. The presence of such tool vibration leads to a poor surface finish, which results in cutting tool damage and the production of irritating and unacceptable noise. In order to reduce tool vibration, a magnetorheological fluid damper was developed that will respond to an applied field with a dramatic change in their rheological behaviour. The essential characteristic of these fluids is their ability to reversibly change from a free-flowing, linear, viscous liquid to a semi-solid with a controllable yield strength within milliseconds when exposed to a magnetic field. The present investigation aims to analyse the behaviour of a tool holder when attached with a magnetorheological damper during the turning operation using analytical and experimental methods. A Mathematical model was developed and the amplitudes of the tool vibration and chip thickness were calculated. Cutting experiments were conducted to study the effect of the magnetorheological damper on tool vibration, chip thickness etc. and to validate the results of the proposed mathematical model. From the results, it was observed that the use of the magnetorheological damper reduces tool vibration effectively and its results matches the results obtained from the numerical method.
\end{abstract}

\section{NOMENCLATURE}

$\begin{array}{ll}m 1 & \text { equivalent mass of tool holder } \\ m 2 & \text { equivalent mass of damper } \\ C 1 & \text { Damping constant of tool holder } \\ C 2 & \text { Damping constant of damper } \\ k_{1} & \text { stiffness of tool holder } \\ x_{1}(t) & \text { chip thickness } \\ K_{2} & \text { stiffness of damper } \\ y_{2}(t) & \text { amplitude of tool vibration } \\ F_{t} & \text { Forces acting in tool holder } \\ F_{d} & \text { Forces acting due to damper } \\ M R & \text { Magnetorheological }\end{array}$

\section{INTRODUCTION}

Tool vibration is a frequent problem in the manufacturing industry, where metal cutting operations take place. Excessive tool vibrations during machining will increase the tool wear and cause poor surface finish. ${ }^{1}$ In metal cutting, tool vibration is the most influential factor affecting the surface quality of the machined surface. ${ }^{2}$ In order to reduce these vibrations and to obtain a better result in terms of surface finish, tool life, and other such factors, a magnetorheological damper was developed. Spencer et $\mathrm{al}^{3}$ were the first among researchers who tested MR Fluid techniques to isolate vibration and it was found that the rheological damper was more effective than the conventional viscous damper. ${ }^{4}$ Wang and $\mathrm{Fei}^{5}$ tried to suppress chatter in a boring bar by using electrorheological fluid. As a result, they developed an on-line chatter detection and control system. Genc and Phule ${ }^{6}$ observed that by varying the parameters associated with MR fluids, such as volume, particle size, fraction of solids etc., the properties of the MR fluids can be varied. It was also found that chatter could be suppressed more effectively by adjusting the damping and natural frequency of the system in a boring bar by using MR Fluid Dampers. ${ }^{7}$ Sathianarayanan et al. ${ }^{8}$ investigated method to improve damping capability by suppressing chatter in boring tools using an MR damper. From the results they concluded that the MR damper reduces the possibility of chatter and improves the stability of the boring operation.

Bajkowski et al. ${ }^{9}$ described, analysed, and numerically simulated a lumped mass model for a damper filled with a magnetorheological fluid and established a solution for the quasi static problem. Chen and $\mathrm{Tsao}^{10}$ proposed a new approach to analyze the stability of cutting processes by considering the 
deformation of the work piece. They used partial differential equations to describe the cutting in the turning process and a set of dynamic equations was considered based on the interaction between the tool and the workpiece. From the numerical results, it was found that the critical chip width of the deformed case was always larger than the rigid body case. Cesmeci et al. ${ }^{11}$ conducted an experimental and theoretical analysis to model the dynamic behavior of an MR damper on a conventional shock machine. A flow analysis of an MR damper was done based on the Bingham plastic constitutive model and the prediction results were compared against the test data. The comparisons showed that there was a very good agreement between the flow model and test results. Choi ${ }^{12}$ presented a hysteresis model for the field-dependent damping force of the MR damper. The measured damping force was compared with the predicted ones from the Bingham model, Bouc-Wen model, and the proposed polynomial model. Furthermore, it was demonstrated that the proposed polynomial model predicted the non-linear hysteresis behavior of the MR damper at various operating conditions fairly well. Chooi and Olutunde ${ }^{13}$ presented a method for obtaining the exact solution representing the flow of MR fluid through an annular gap.

Kwok et al. ${ }^{14}$ presented a new model for a magnetorheological damper to represent the hysteretic relationship between the damping force and the velocity. By using this new model, complexities arising from a larger number of model parameters when using the Bouc-Wen model were removed and the results obtained by this model matched well the experimental data. Liao and Hand ${ }^{15}$ studied the application of an MR fluid damper for the vibration control of a Single-degree-of-freedom system. The characteristics of the MR damper were investigated using analytical and experimental methods and compared with those of the system with a conventional viscous damper. From the results, it was observed that the MR damper provided effective damping for vibration isolation or suppression. Piotrowska et al. ${ }^{16}$ developed a novel two-degree-of-freedom model for the micro turning processes to show the effect of process kinematics and tool edge serration in simulating the tool-work piece system behaviour. Sam Paul et al. ${ }^{17,18}$ used a magnetorheological damper to reduce tool vibration during hard turning with minimal fluid application. For designing magnetorheological damper, they considered parameters like the shape of the plunger, the viscosity of the oil, the size of the particle, and the type of current. They also observed that the magnetorheological damper had a considerable influence on tool wear. ${ }^{19}$ From the results, they observed that using Magneto rheological fluid damper, tool vibration can be reduced and cutting performance can be improved effectively. Sekar et al. ${ }^{20}$ presented stability analysis in turning process with a coupled dynamic model of cutting tool and tailstock supported workpiece. The effect of the cutting position, workpiece dimensions, cutter flexibility, and cutter damping on the dynamic stability was presented with the dynamic model and they observed that the experimental chatter establishes the stable states accurately in rough turning operations for the proposed model.

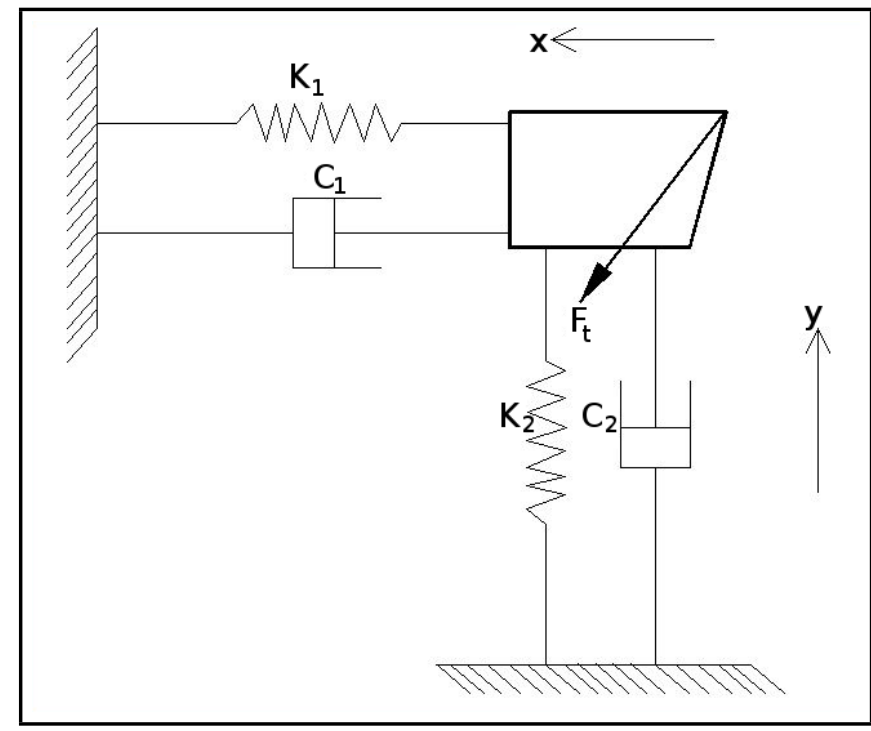

Figure 1. Model of the tool with the damper for a rigid work piece.

The present investigation aimed at analysing a tool with the magnetorheological damper by using analytical and experimental methods that will assist hard turning to suppress tool vibration. When an electric field was applied to the MR fluids, the fluid became a semisolid and behaved as a viscoelastic spring with non-linear vibration characteristics. This transition was reversible and could be achieved in a few milliseconds and the deformation modes of the magnetorheological fluids depend on the applied electric field. To validate analytical model, cutting experiments were conducted during turning of AISI 4340 steel of $46 \mathrm{HRC}$ using hard metal insert with sculptured rake face. Electrical and compositional parameters were selected based on the information available in the literature. ${ }^{18}$ The MR Fluid damper developed appears to hold promise as a means to suppress tool vibration.

\section{THEORETICAL ANALYSIS OF TOOL WITH DAMPER}

In the turning operation, the work piece was considered as a rigid member and parameters like chip thickness, tool vibration are affected by the dynamic parameters of cutting tool.

\subsection{Development of the Mathematical Model}

The model of the turning tool with the damper for a rigid work piece is shown in Fig. 1. They are represented with the governing equations as follows:

$$
\begin{gathered}
m_{1} \ddot{x}_{1}(t)+c_{1} \dot{x}_{1}(t)+k_{1} x_{1}(t)=-F_{t} ; \\
m_{2} \ddot{y}_{2}(t)+c_{2} \dot{y}_{2}(t)+k_{2} y_{2}(t)=F_{d} ;
\end{gathered}
$$

Equations (1) and (2) represent the equation of motion for tool holder and the magnetorheological damper respectively. Here, parameters $m_{1}, c_{1}, k_{1}$, and $m_{2}, c_{2}, k_{2}$ are the equivalent mass, damping, stiffness of tool holder and damper respectively. The chip thickness is represented as:

$$
x_{1}=A \sin \omega t+B \cos \omega t ;
$$


Table 1. Displacement, velocity, and acceleration values.

\begin{tabular}{|c|c|}
\hline$t=0$ & $t=\frac{\pi}{2 \omega}$ \\
\hline$x_{1}=B$ & $x_{1}=A$ \\
$y_{2}=D$ & $y_{2}=E$ \\
$\dot{x}_{1}=\omega A$ & $\dot{x}_{1}=-\omega B$ \\
$\dot{y}_{2}=\omega E$ & $\dot{y}_{2}=-\omega D$ \\
$\ddot{x}_{1}=-\omega_{2} B$ & $\ddot{x}_{1}=-\omega_{2} A$ \\
$\ddot{y}_{2}=-\omega_{2} D$ & $\ddot{y}_{2}=-\omega_{2} E$ \\
\hline
\end{tabular}

The amplitude of the tool vibration was represented as;

$$
y_{2}=E \sin \omega t+D \cos \omega t
$$

Sekar et al. ${ }^{10}$ derived the equation for cutting force, which was given as:

$$
\begin{aligned}
& F_{t}=C b\left\{h_{0}-\left(x_{1}(t)-x_{2}(t)\right)-\right. \\
& \left.-\left(x_{1}(t-\tau)-x_{2}(t-\tau)\right)\right\} \cos \theta .
\end{aligned}
$$

Spencer et al. ${ }^{11}$ derived the equation of damping force, which was given as:

$$
F_{d}=C b h_{0}\left\{c_{0} v-k_{0}\left(y-y_{0}\right)+y z\right\} \sin \theta .
$$

In this investigation, two time spans, which represented the initial time $(t=0)$ and the final time $(t=\pi / 2 \omega)$, were considered in order to study the machining time. The values of displacement, velocity, and acceleration at two time spans presented in Table 1 are substituted in Eqs.(3) and (4) to calculate constants $\mathbf{A}$ and $\mathbf{B}$.

Substituting the necessary values of Table 1 in the Eq. (3) and further simplifying the equations resulted in the following solution:

$$
\begin{gathered}
\mathbf{B}=\frac{-F_{t}}{\left[-m_{1} \omega^{2}+\omega c_{1} \frac{\left(k_{1}-m_{1} \omega^{2}+\omega c_{1}\right)}{\left(k_{1}-m_{1} \omega^{2}-\omega c_{1}\right)}+k_{1}\right]} \\
\mathbf{A}=\left[\frac{\left(k_{1}-m_{1} \omega^{2}+\omega c_{1}\right)}{\left(k_{1}-m_{1} \omega^{2}-\omega c_{1}\right)}\right] \\
{\left[\frac{-F_{t}}{-m_{1} \omega^{2}+\omega c_{1} \frac{\left(k_{1}-m_{1} \omega^{2}+\omega c_{1}\right)}{\left(k_{1}-m_{1} \omega^{2}-\omega c_{1}\right)}+k_{1}}\right] .}
\end{gathered}
$$

Similarly following results were obtained after simplifying Eq. (4).

$$
\begin{gathered}
\mathbf{D}=\frac{F_{d}}{\left[-m_{2} \omega^{2}+\omega c_{2} \frac{\left(k_{2}-m_{2} \omega^{2}+\omega c_{2}\right)}{\left(k_{2}-m_{2} \omega^{2}-\omega c_{2}\right)}+k_{2}\right]} ; \\
\mathbf{E}=\left[\frac{\left(k_{2}-m_{2} \omega^{2}+\omega c_{2}\right)}{\left(k_{2}-m_{2} \omega^{2}-\omega c_{2}\right)}\right] \\
{\left[\frac{F_{d}}{-m_{2} \omega^{2}+\omega c_{2} \frac{\left(k_{2}-m_{2} \omega^{2}+\omega c_{2}\right)}{\left(k_{2}-m_{2} \omega^{2}-\omega c_{2}\right)}+k_{2}}\right] .}
\end{gathered}
$$

$F_{t}=527 \mathrm{~N}, m_{1}=0.8 \mathrm{Kg}, \omega=\frac{2+\pi+500}{60}=52.3 \mathrm{~Hz}$, $k_{1}=20000 \mathrm{~N} / \mathrm{mm}, \omega_{n}=5200 \mathrm{~Hz}, C=0.01 \mathrm{Ns} / \mathrm{m}$. From Eqs. (3), (4), and (8) to (10), the chip thickness and amplitude of tool vibration for the tool holder with the magnetorheological damper were calculated. On substituting the constant values and by applying boundary conditions, it was found that the amplitude of tool vibration $\left(y_{2}\right)$ was found to be $0.029 \mathrm{~mm}$ and the chip thickness $\left(X_{1}\right)$ was observed to be $1.25 \mathrm{~mm}$.

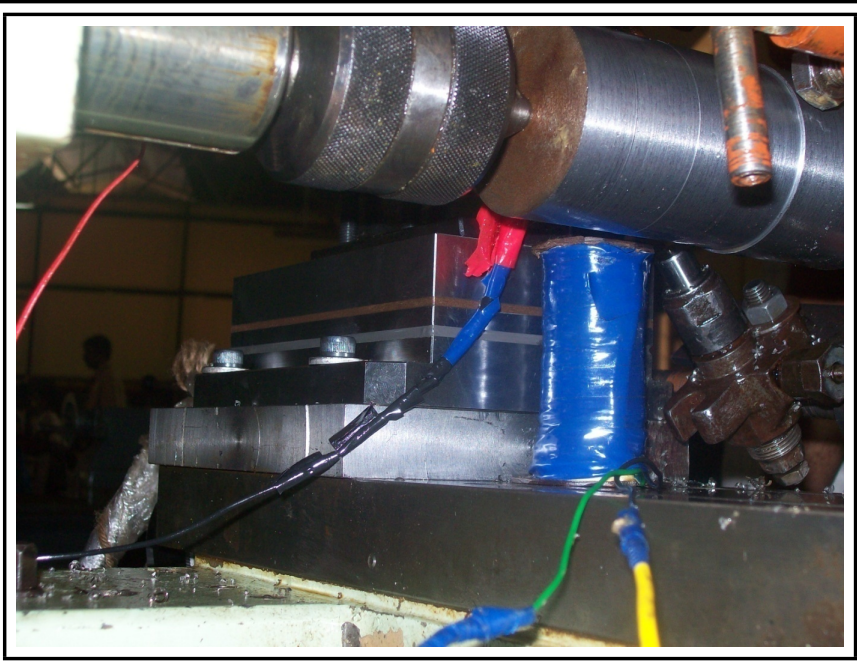

Figure 2. Photograph of the experimental setup.

\section{THE MAGNETORHEOLOGICAL DAMPER}

Magnetorheological (MR) fluids belong to a class of controllable fluids. When magnetorheological fluids are exposed to a magnetic field, they have the ability to reversibly change from a viscous liquid to a semi-solid with controllable yield strength in milliseconds. The MR fluid damper acts as a viscoelastic spring with a non linear vibration characteristics that are controlled by the composition of the magnetorheological fluid, shape of the plunger and the electrical parameters of magnetizing field.

\subsection{Fabrication of the Magnetorheological Damper}

The MR damper apparatus consist of a cylinder in which iron particles mixed with oil are filled. The cylinder encloses a piston, which float with the piston head at the center of the cylinder. The piston rod of the apparatus was fixed to the tool with the help of a clamping device. A coil through which current supplied is wound around the outer surface of the cylinder. Iron particles of 40 microns size, SAE 40 oil, and an AC current with $30 \mathrm{~V}$ supply were used in this study. The MR damper setup was interfaced with the lathe with the help of a clamping device. Figure 2 presents the photograph of the experimental setup and the photograph of the MR Fluid Damper is shown in Fig. 3.

\subsection{Selection of Tool and Workpiece}

The workpiece material was AISI 4340 steel, which was hardened to $46 \mathrm{HRC}$ by heat treatment. Bars that were $75 \mathrm{~mm}$ in diameter and $320 \mathrm{~mm}$ in length were used. The Chemical composition of AISI 4340 Steel in weight percent are $0.41 \%$ C, $0.87 \% \mathrm{Mn}, 0.28 \% \mathrm{Si}, 1.83 \% \mathrm{Ni}, 0.72 \% \mathrm{Cr}, 0.20 \% \mathrm{Mo}$, and rest is Fe. ${ }^{21}$ The tool holder had the specification PSBNR 2525 M12. Multicoated hardmetal inserts with sculptured rake face geometry with the specification SNMG 120408 MT TT5100 from Taegu Tec were used. ${ }^{22}$ 


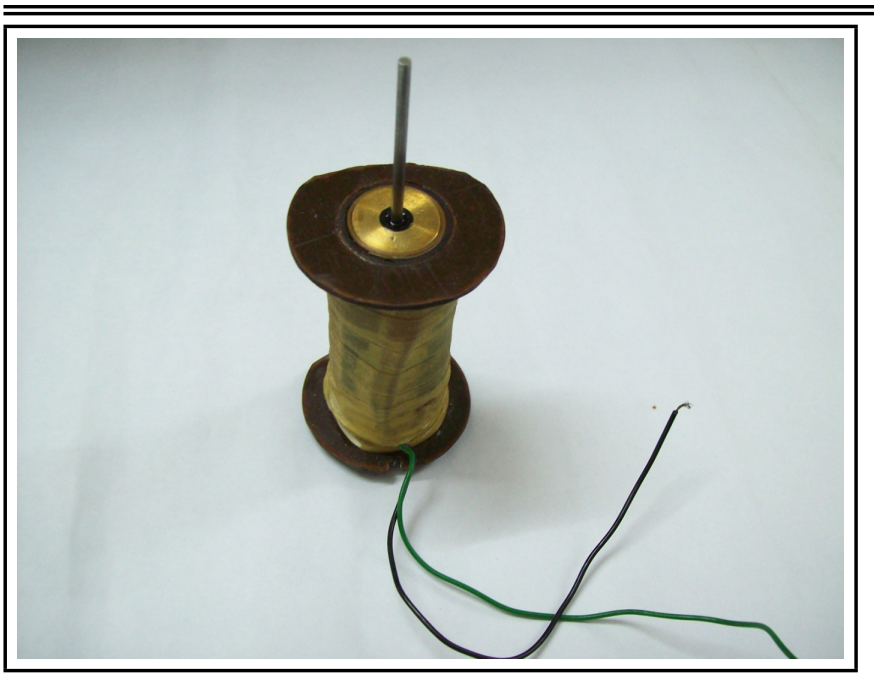

Figure 3. Photograph of the MR Damper.

\subsection{Experimental Setup}

To study the effect of the MR Damper on tool vibration and chip thickness, an 8 run experiment was designed based on the Taguchi technique. Experiments were carried out during hard turning with minimal fluid application. Cutting velocity and feed rate were varied at two levels. The cutting velocity was applied at 60 and $70 \mathrm{~m} / \mathrm{min}$ and the feed rate was applied at 0.07 and $0.08 \mathrm{~mm} / \mathrm{rev}$ and the depth of cut was kept at $0.6 \mathrm{~mm}$. The Cutting velocity and feed rate combinations were arrived at based on the results of preliminary experiments and the recommendations of the cutting tool Manufacturers $\mathrm{M} / \mathrm{s}$. Taegutec India (P) Ltd. who were supporting this research work. These ranges are prescribed for turning in semi finish range for the tool-work combination. Also two dimensionallysimilar plungers were made, one with OHNS and the other one with Stainless steel 410(SS410). The pressure at the Fluid applicator was kept at $100 \mathrm{MPa}$, the rate of fluid application at $2 \mathrm{ml} / \mathrm{min}$, the frequency of pulsing at 500 pulses $/ \mathrm{min}^{23}$ Three different inserts were used in the experimentation and each experiment lasted for 2 minutes. Amplitude of tool vibration was measured by using a piezoelectric vibrometer pickup mounted at the top of the tool holder. Since the vibration, particularly in the radial direction, is known to have a deleterious effect on the machined surface texture, ${ }^{24}$ the amplitude of tool vibration in vertical direction was measured in this study. The main cutting force was measured using a Kistler type 9257B dynamometer. Since the feed force and thrust force are small in magnitude, least harmful and least significant, the cutting force acting in tangential direction (Y- direction), which was called as main cutting force, was considered in this study. ${ }^{25}$

Surface Roughness was measured using Mahr TR100 surface roughness tester of type MarSurf GD 25. There are various simple surface roughness amplitude parameters used in industry, such as roughness average (Ra), root-mean square roughness (Rq), maximum peak-to-valley roughness (Ry or Rmax), etc. The average roughness (Ra) averages all peaks and valleys of the roughness profile, and then neutralizes the few outlying points so that the extreme points have no signifi-

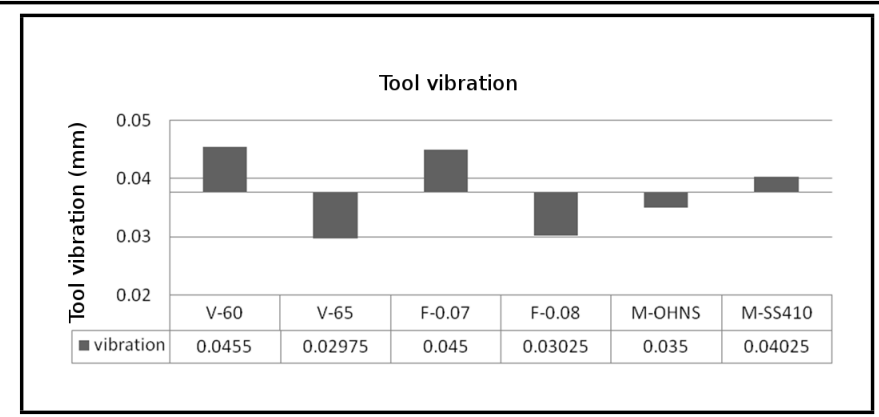

Figure 4. Relative significance of input parameters on the amplitude of tool vibration.

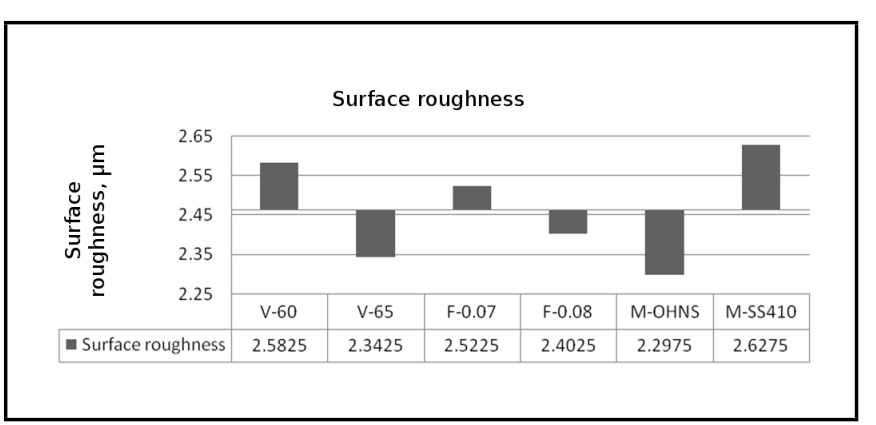

Figure 5. Relative significance of input parameters on surface roughness.

cant impact on the final results. Since it's a simple and effective method for monitoring surface texture and ensuring consistency in measurement of multiple surfaces, Ra was selected to express the surface roughness in this study. When the relief face of a cutting tool rubs against the workpiece, flank wear was created on this face and this type of tool wear was caused by an abrasion mechanism and it progresses gradually. Flank wear impared the accuracy of the parts machined because it causes deflection of the cutting tool. ${ }^{26}$ Flank wear is usually maximum at the extremities of the cutting edge and in the central zone the wear land it is fairly uniform. Also, the Flank wear land width $\left(V B_{B}\right)$ was the criterion of tool life according to the ISO 3685 (1993) standard. ${ }^{27}$ Hence, in this study, the average flank wear land width $\left(V B_{B}\right)$ was considered and measured. Chip thickness was measured using tool makers microscope.

\section{RESULTS AND DISCUSSION}

Cutting experiments were carried out with two replications and the results are summarized in Table 2.

The relative significance of input parameters on the amplitude of tool vibration is shown in Figs. 4 and 5 presents the relative significance of the input parameters on surface roughness. The relative significance of input parameter on chip thickness, cutting force, and tool wear are shown in Figs. 6 to 8 , respectively. The experimental results were analyzed using Qualitek-4 and the levels of input parameters for achieving minimum tool vibration, tool wear, cutting force, chip thickness, and surface roughness are presented in Table 3.

Cutting experiments were conducted with the input parameters kept at the levels indicated in Table 3 and the performance 
Table 2. Experimental conditions and results.

\begin{tabular}{|c|c|c|c|c|c|c|c|c|}
\hline $\begin{array}{l}\text { Run } \\
\text { Run }\end{array}$ & $\begin{array}{l}\text { Velocity } V \\
\mathrm{~m} / \mathrm{min} .\end{array}$ & $\begin{array}{c}\text { Feed rate } F \\
\mathrm{~mm} / \mathrm{rev}\end{array}$ & $\begin{array}{c}\text { Damping } \\
\text { Material } M\end{array}$ & $\begin{array}{l}\text { Amplitude of Tool } \\
\text { Vibration mm }\end{array}$ & $\begin{array}{l}\text { Surface roughness } \\
\qquad R a \mu \mathrm{m}\end{array}$ & $\begin{array}{l}\text { Chip width } \\
\text { mm }\end{array}$ & $\begin{array}{l}\text { Cutting } \\
\text { Force N }\end{array}$ & $\begin{array}{l}\text { Tool Wear } \\
V B_{B} \mathrm{~mm}\end{array}$ \\
\hline 1 & 60 & .07 & OHNS & 0.049 & 2.31 & 1.21 & 44.56 & 0.018 \\
\hline 2 & 60 & .07 & SS410 & 0.054 & 3.15 & 2.05 & 48.77 & 0.013 \\
\hline 3 & 60 & .08 & OHNS & 0.037 & 2.28 & 1.18 & 33.67 & 0.017 \\
\hline 4 & 60 & .08 & SS410 & 0.042 & 2.59 & 1.89 & 33.86 & 0.006 \\
\hline 5 & 65 & .07 & OHNS & 0.032 & 2.18 & 1.20 & 32.96 & 0.003 \\
\hline 6 & 65 & .07 & SS410 & 0.045 & 2.45 & 1.40 & 35.92 & 0.013 \\
\hline 7 & 65 & .08 & OHNS & 0.022 & 2.42 & 1.10 & 32.50 & 0.001 \\
\hline 8 & 65 & .08 & SS410 & 0.020 & 2.32 & 1.60 & 33.34 & 0.014 \\
\hline
\end{tabular}

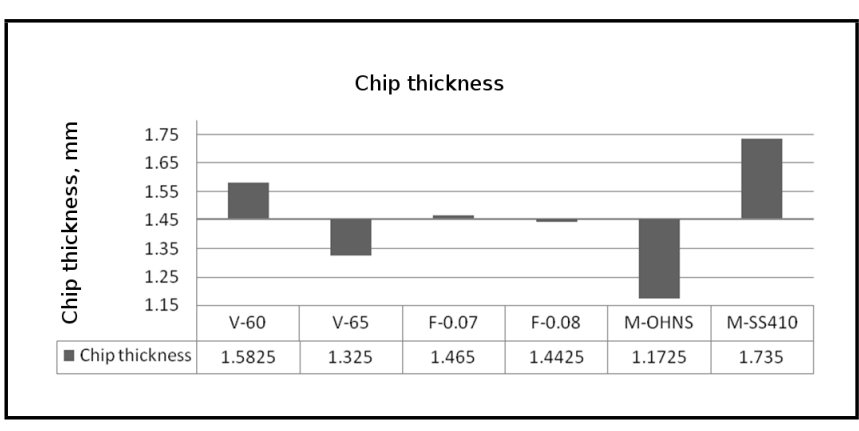

Figure 6. Relative significance of input parameters on chip thickness.

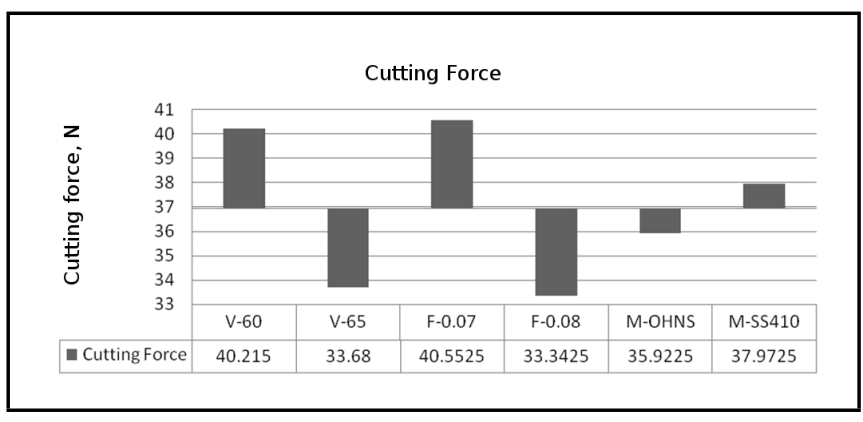

Figure 7. Relative significance of input parameters on the cutting force.

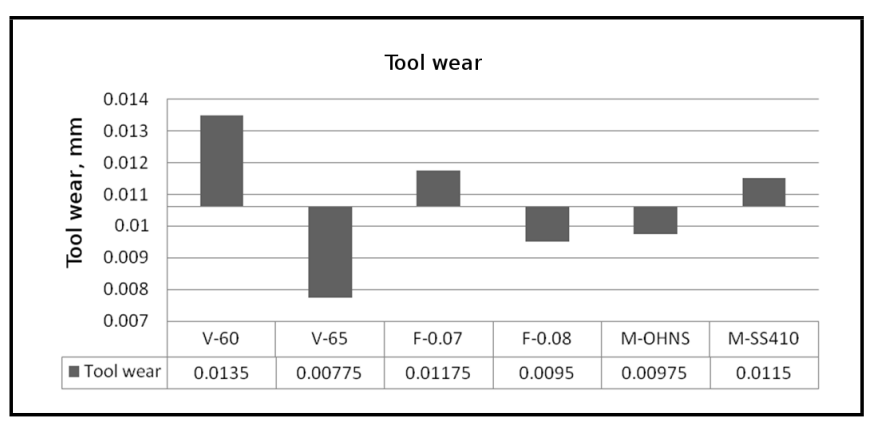

Figure 8. Relative significance of input parameters on tool wear.

Table 3. Levels of input parameters for getting an optimum performance.

\begin{tabular}{|c|c|c|c|}
\hline Desired outcome & $\begin{array}{c}\text { Cutting Velocity } \\
\mathrm{mm} / \mathrm{min} .\end{array}$ & $\begin{array}{c}\text { Feed rate } \\
\mathrm{mm} / \mathrm{rev} .\end{array}$ & Material \\
\hline To Improve Surface Finish & 65 & 0.08 & OHNS \\
\hline To reduce Tool Vibration & 65 & 0.08 & OHNS \\
\hline To reduce Chip thickness & 65 & 0.08 & OHNS \\
\hline To reduce Cutting Force & 65 & 0.08 & OHNS \\
\hline To reduce Tool wear & 65 & 0.08 & OHNS \\
\hline
\end{tabular}

Table 4. Comparison of performance with an MR damper and without a damper.

\begin{tabular}{||c|c|c|c||}
\hline Parameters & $\begin{array}{c}\text { WITH } \\
\text { DAMPER }\end{array}$ & $\begin{array}{c}\text { WITH OUT } \\
\text { DAMPER }\end{array}$ & Effect \\
\hline $\begin{array}{c}\text { Amplitude of Tool } \\
\text { vibration, mm }\end{array}$ & 0.027 & 0.049 & $45 \%$ reduction \\
\hline $\begin{array}{c}\text { Surface roughness } \\
R a, \mu \mathrm{m}\end{array}$ & 2.501 & 3.213 & $22 \%$ reduction \\
\hline Chip thickness, mm & 1.26 & 1.40 & $10 \%$ reduction \\
\hline Main Cutting Force, $\mathrm{N}$ & 36.67 & 55.31 & $34 \%$ reduction \\
\hline Tool wear $V B_{B}, \mathrm{~mm}$ & 0.0165 & 0.0227 & $27 \%$ reduction \\
\hline
\end{tabular}

was compared with the cutting performance during conventional minimal fluid application without the magnetorhological damper. A comparison of the cutting performance for the two cases is shown in Table 4.

During the turning operation, higher cutting forces occur than the usual due to the increase in hardness of workpiece and this increase in cutting force reduces the rigidity of the cutting tool. Any system that can oppose the movement of the tool in the downward direction can provide better damping. From Table 3, it was observed that MR Fluid damper reduced the cutting force by $34 \%$. This damping force increased the stiffness of the machine tool structure, provided better damping action, and reduced the total energy to perform cutting operation. Since the dynamic nature of main cutting force acting on the cutting tool during the hard turning decreases due to increase in stiffness of the machine tool structure, vibration induced in the machining tool also decreases by $45 \%$ effectively.

When the bouncing of the tool in and out of the work piece decreased, there was a reduction in the irregularities of the surface. As a consequence, surface finish improved considerably by $22 \%$ and this smooth surface avoids the risk of crack initiation. Furthermore, when the dynamic rigidity of the cutting tool increases due to increase in stiffness; the tool had more life than a tool machining under vibrating conditions. This increase in tool life results to decrease in tool wear and from the results it was observed that tool wear reduces by $27 \%$.

The strength of the damping depends on the magnetic field which in turn depends on the supply voltage and oil used. Moreover, the magnetic field can also be varied according to the required intensity of damping. The higher the supply voltage, the higher the strength of the magnetic field and the better the damping capability. Also voltage supplied to the core more than the allowable limit has to be avoided as this would lead to a condition wherein the MR fluid will become a solid mass and loses its damping capability altogether. In this study, a 
magnetorheological damper with 40 micron size iron particles, SAE 40 oil, $30 \mathrm{~V}$ supply voltage was used. ${ }^{17}$

It appears that an SAE40 oil provides better damping and better cutting performance in terms of vibration and surface roughness. A fluid with a higher viscosity can offer higher resistance to the movement of the plunger and hence offer a better surface finish. Also, it appears that the magnetic particle in the MR fluid should have a minimum size to offer better performance. In the present investigation, iron particles of $75 \mathrm{mi}-$ crons size were used to investigate the effect of damper on cutting performance. If the size of the particles in the MR fluid was very small, there would be a possibility of magnetized particles sticking together to form a solid mass when magnetized. But if the size of the particle was sufficiently high, the tendency to form a solid block reduced. There will a good distribution of the magnetized particles with the fluid occupying the region in between and this distribution of magnetized particles in a pool of the fluid provides better resistance to the movement of the plunger, which lead to better reduction in tool wear and improvement in surface finish. Also, based on the availability and affordability of the iron particles size in the market, this size was chosen and used.

From the results, it was observed that the introduction of a damper made of OHNS brought forth low vibration levels and better cutting performance when compared to a damper made of stainless steel 410 . However, while choosing a ferromagnetic material for making the plunger, care should be exercised to see that the material has low magnetic retentivity. If the material chosen has high magnetic retentivity, it will tend to become a permanent magnet under the influence of the magnetizing field and will attract the ferromagnetic particles even without the magnetizing field.

The results obtained using experimental method were verified by using the analytical method. Based on the experimental method, it was observed that without considering the damper, deflection was $0.049 \mathrm{~mm}$ and chip width was found to be $1.40 \mathrm{~mm}$, whereas by considering damper, the deflection was $0.027 \mathrm{~mm}$ and chip thickness was found to be $1.26 \mathrm{~mm}$. This result was further validated using the analytical approach where the deflection and chip thickness was found to be $0.029 \mathrm{~mm}$ and $1.25 \mathrm{~mm}$, respectively when considering the tool with damper. Hence, from the analyical and experimental results, it is infered that the performance of the magnetorheological damper holds good for turning of hardened AISI 4340 steel.

\section{CONCLUSION}

In the present investigation, the effect of magnetoheological damper on tool vibration and chip width were analysed and tested using analytical and experimental methods. A 9 run experiment was conducted to study the effect of the magnetorheological damper on cutting performance during hard turning with minimal fluid application and the results were compared with analytical solution. Also the cutting performance obtained using the magnetorheological damper was compared with the cutting performance during conventional minimal fluid application without damper. From the present study, the following conclusions were drawn:

1. The magnetorheological damper reduces tool vibration, cutting force, chip thickness, and surface roughness effectively during turning of hardened AISI 4340 steel. The damping capability of turning tool and the efficiency of turning operation have been improved considerably.

2. For achieving better damping capability and cutting performance, the damper is to be fabricated with Ferro particles mixed with an oil specified by SAE, magnetized with current, and provided with a suitable plunger made of OHNS steel.

3. A mathematical model is developed for turning tool with damper conditions, which enables one to arrive at the analytical solution of obtaining chip thickness and deflection of the tool holder and thereby understand the stability limits for a cutting tool and the work piece.

\section{ACKNOWLEDGEMENTS}

The authors are grateful to the Centre for Design and Manufacturing Engineering (CRDM) in the Department of Mechanical Engineering at Karunya University for providing the facilities to carry out the research work. The authors also thank $\mathrm{M} / \mathrm{s}$ Taegu Tec for supporting this research work by supplying cutting tools at concessional rates.

\section{REFERENCES}

1 Altintas, Y. Manufacturing Automation: Metal Cutting Mechanics, Machine Tool Vibrations and CNC Design, Cambridge University Press, London, (2000).

2 Ghani, A. K., Choudhury, I. A., and Husni. Study of tool life, surface roughness and vibration in machining nodular cast iron with ceramic tool, Journal of Materials Processing Technology, 127 (1), 17-22, (2002). http://dx.doi.org/10.1016/S0924-0136(02)00092-4

3 Spencer Jr, B. F., Dyke, S. J., Sam, M. K., and Carlson, J. D. Phenomenological Model of a magnetorheological damper, Journal of Engineering Mechanics, 123 (3), 230-238, (1997). http://dx.doi.org/10.1061/(ASCE)07339399(1997)123:3(230)

4 Torsten., Butz., and von Stryk, O. Modelling and Simulation of Rheological Fluid Devices, Preprint SFB-438991 1, Sonderforschungsbereich 438, Techniche Univerität München, (1999).

5 Wang, M., and Fei, R. Y. Chatter suppression based on nonlinear vibration characteristic of electrorheological fluids, International Journal of Machine Tools and Manufacture, 39 (12), 1925-1934, (1999). http://dx.doi.org/10.1016/j.jmatprotec.2008.04.037 
6 Genc, S., and Phule, P. P. Rheological Properties of Magnetorheological Fluids, Smart Materials and Structures, 11 (1), 140-146, (2002). http://dx.doi.org/10.1088/0964$1726 / 11 / 1 / 316$

7 Deqing Mei., Tianrong Kong., Albert, J., and Shih Zichen Chen. Magnetorheological fluid-controlled boring bar for chatter suppression, Journal of materials processing technology, 209 (4), 1861-1870, (2009). http://dx.doi.org/10.1016/j.jmatprotec.2008.04.037

8 Sathianarayanan, D., Karunamoorthy, L., Srinivasan, J., Kandasami, G. S., and Palanikumar, K. Chatter Suppression in Boring Operation Using Magnetorheological Fluid Damper, Materials and Manufacturing processes, 23 (4), 29-335, (2008). http://dx.doi.org/10.1080/10426910701860897

9 Bajkowski, J., Nachman, J., Shillor, M., and Sofonea, M. A model for a magnetorheological damper, Mathematical and Computer Modelling, 48 (12), 56-68, (2007). http://dx.doi.org/10.1016/j.mcm.2007.08.014

10 Chen, C. K., and Tsao, Y. M. A stability analysis of regenerative chatter in turning process without using tailstock, Int J Adv Manuf Technol, 29 (7-8), 648-654, (2006). http://dx.doi.org/10.1007/s00170-005-2573-5

11 Cesmeci, S., and Engin, T. Modeling and testing of a fieldcontrollable magnetorheological fluid damper, International Journal of Mechanical Sciences, 52 (8), 1036-1046, (2010). http://dx.doi.org/10.1016/j.ijmecsci.2010.04.007

12 Choi, S. B., Lee, S. K., and Park, Y. P. A hysteresis model for the field-dependent damping force of a magnetorheological damper, Journal of Sound and vibration, 245 (2), 375-383, (2001). http://dx.doi.org/10.1006/jsvi.2000.3539

13 Chooi, W. W., and Olutunde, O. S. Mathematical Modeling, Analysis, and Design of Magnetorheological Dampers, Journal of Vibration and Acoustics, 131 (6), 1-10, (2009). http://dx.doi.org/10.1115/1.3142884

14 Kwok, N. M., Ha, Q. P., Nguyen, T. H., Li, J., and Samali, B. A novel hysteretic model for magnetorheological fluid dampers and parameter identification using particle swarm optimization, Sensors and Actuators A: Physical, 132 (2), 441-451, (2006). http://dx.doi.org/10.1016/j.sna.2006.03.015

15 Liao, W., and Hand Lai, C. Y. Harmonic analysis of a magnetorheological damper for vibration control, Smart Materials and Structures, 11, 288-296, (2002). http://dx.doi.org/10.1088/0964-1726/11/2/312

16 Piotrowska, I., Brandt, C., Karimi, H., and Maass. P. Mathematical model of micro turning process, Int J Adv Manuf. Technol, 45 (1), 33-40, (2009). http://dx.doi.org/10.1007/s00170-009-1932-z
17 Sam Paul, P., and Varadarajan,. A. S. Effect of magneto rheological damper on tool vibration during hard turning., Frontiers in Mechanical Engineering, 7 (4), 410-416, (2012). http://dx.doi.org/10.1007/s11465-012-0341-4

18 Sam Paul, P., Varadarajan,. A. S., Ajay vasanth, X., and Lawrance G. Effect of magnetic field on damping ability of magnetorheological damper during hard turning, Archives of civil and mechanical Engineering, 14 (3), 433-444, (2014). http://dx.doi.org/10.1016/j.acme.2013.11.001

19 Sam Paul, P., Varadarajan, A. S., and Mohanasundaram, S. Effect of magnetorheological fluid on tool wear during hard turning with minimal fluid application, Archives of civil and mechanical Engineering, 15(1), 124132, (2015). http://dx.doi.org/10.1016/j.acme.2014.03.007 http://dx.doi.org/10.1016/j.acme.2014.03.007

20 Sekar, M., Srinivas, J., Kotaiah, KR., and Yang, S. H. Stability analysis of turning process with tailstock-supported workpiece, Int J Adv Manuf Technol, 43, 862-871, (2009). http://dx.doi.org/10.1007/s00170-008-1764-2

21 Sam Paul, P., and Varadarajan, A. S. A multi-sensor fusion model based on an artificial neural network to predict tool wear during hard turning, Journal of Engineering Manufacture, 226 (5), 853-860, (2012). http://dx.doi.org/10.1177/0954405411432381

22 Sam Paul, P., and Varadarajan, A. S. Performance evaluation of hard turning of AISI 4340 steel with minimal fluid application in the presence of semi-solid lubricants, Journal of Engineering Tribology, 227 (7), 739-748, (2013). http://dx.doi.org/10.1177/1350650112468376

23 Varadarajan, A. S., Philip, P. K., and Ramamoorthy, B. Investigations on hard turning with minimal cutting fluid application (HTMF) and its comparison with dry and wet turning, International Journal of Machine Tools and Manufacture, 42 (2), 193-200, (2002). http://dx.doi.org/10.1016/S0890-6955(01)00119-5

24 Moon, K. S., and Sutherland, J. W. The Origin and Interpretation of Spatial Frequencies in a Turned Surface Profile, Journal of Engineering for Industry, Trans. ASME, 116 (3), 340-347, (1994). http://dx.doi.org/10.1115/1.2901950

25 Kistler. Guide to the measurement of force, The institute of Measurement and Control ISBN 090445728 1, London, (1998).

26 Stephenson, D. A., and Agapiou, J. S. Metal Cutting Theory and Practice, Marcel Dekker, New York, (1997).

27 International Organization for Standardization, Tool-life testing with single point turning tools, ISO 3685-1993 (E), 2nd Edition, Case Postale 56, CH-1211 Geneva 20, Switzerland,(1993). URL https://www.evs.ee/preview/iso3685-1993-en.pdf 